\title{
El reconocimiento de los derechos de los pueblos indígenas de El Salvador entre el genocidio continuado y el reencuentro de nuestras raíces
}

\author{
Gustavo Pineda ${ }^{1}$
}

Recibido en noviembre de 2015, aceptado en diciembre de 2015.

\begin{abstract}
“...Somos un pueblo que ha sido sometido al exterminio cuyos hechos más conocidos se ubican en el genocidio de 1932 donde nuestras comunidades sufrieron graves masacres...Por eso, somos un pueblo en resistencia y nos negamos a morir. ¿Qué mueve a un grupo humano para exterminar a otro? no hay dios ni razón ni ley que justifique esto; si se nos niega a los pueblos indígenas, se están negando todas y todos salvadoreños y salvadoreñas pues somos un solo río de 400 voces y casi todos en este país tenemos sangre indígena...nuestras abuelas y abuelos con su ciencia, transformaron el maíz haciéndolo más grande para que pudiéramos comer todas y todos. Tenemos derecho a existir y a continuar con nuestra semilla, a reproducirnos como se reproduce este maíz. Estas son nuestras montañas, éstos nuestros ríos, esta es nuestra Madre Tierra, por eso necesitamos hacer ley la palabra justa, esa palabra que danza con las fuerzas del cosmos, con la sabiduría del movimiento inteligente, con la armonía”. ${ }^{2}$
\end{abstract}

\begin{abstract}
Resumen
Este artículo revisa la ruta crítica hacia el reconocimiento de los pueblos indígenas de El Salvador a partir de las leyes coloniales de protección, pasando a la supresión de tales regulaciones, hasta las leyes de extinción de las tierras comunales durante el siglo XIX. Posteriormente, se menciona el genocidio de 1932 y la amnistía concedida a sus autores, así como el reconocimiento de los derechos de los pueblos indígenas en el derecho interno e internacional en los primeros años de este siglo. El artículo concluye enumerando los pasos a tomar con las comunidades indígenas para cambiar su realidad y lograr la visión intercultural como país.
\end{abstract}

Palabras claves

Negación, reconocimiento, normativa, pueblos indígenas.

1. Abogado, miembro del Departamento de Pueblos Indígenas de la Secretaría de Cultura de la Presidencia. E-mail: gpineda@cultura.gob.sv

2. Ordenanza Municipal sobre Derechos de las Comunidades Indígenas asentadas en el municipio de Nahuizalco. (Alcaldía de Nahuizalco, Sonsonate, 2010) preámbulo de versión aprobada por el Consejo Municipal el 24 de Octubre de 2010. 


\begin{abstract}
:
This article reviews the critical path towards the recognition of indigenous peoples in El Salvador from colonial protection laws, through the abolition of such regulations, to the laws of extinction of communal lands during the nineteenth century. Subsequently, the genocide of 1932 and the amnesty granted to the perpetrators as well as the recognition of the rights of indigenous peoples in national and international law in the early years of this century is mentioned. The article concludes by listing the steps to take with indigenous communities to change their reality and to achieve intercultural vision as a country.
\end{abstract}

Keywords:

Denial, recognition, legislation, indigenous peoples.

El tema de los pueblos indígenas de El Salvador, ha estado marcado por dos aspectos: el primero es una dinámica de reiterada negación tanto en los informes oficiales -de antes de 2009-, como en la percepción gran parte de los salvadoreños. Es decir, el discurso homogenizador de las repúblicas nacientes del siglo XIX, determinó la cultura de los salvadoreños y promovió un enfoque monocultural de manera que el "tema indígena" se presenta como algo extraño y ajeno al común de la gente. El segundo, lo constituyen los acontecimientos de 1932 que han determinado gran parte de nuestra dinámica como nación durante el siglo pasado y los inicios del presente. El levantamiento indígena que provocó un genocidio ${ }^{3}$ como respuesta en 1932, nos distingue como país del resto de Centroamérica por dos cosas: en primer lugar, este levantamiento indígena está fuertemente ligado a la pasada guerra civil y ésta a los cambios actuales. Podemos decir que, los pueblos indígenas de El Salvador fueron los primeros en aportar su sacrificio para que ocurrieran cambios en el país y sin embargo, siguen marginados y negados. En segundo lugar, en ningún otro país centroamericano ha ocurrido un genocidio contra pueblos indígenas de tal magnitud y que ha proseguido bajo otra forma, pues si en 1932 el genocidio se

3. Sostengo que se trata de un genocidio ya que todas las versiones serias de lo ocurrido, apuntan al exterminio intencional de la población indígena. En la Convención para la Prevención y Sanción del Delito de Genocidio (Adoptada y abierta a la firma y ratificación, o adhesión, por la Asamblea General en su resolución 260 A (III), de 9 de diciembre de 1948) este delito se define en el Artículo II: En la presente Convención, se entiende por genocidio cualquiera de los actos mencionados a continuación, perpetrados con la intención de destruir, total o parcialmente, a un grupo nacional, étnico, racial o religioso, como tal:

a) Matanza de miembros del grupo;

b) Lesión grave a la integridad física o mental de los miembros del grupo;

c) Sometimiento intencional del grupo a condiciones de existencia que hayan de acarrear su destrucción física, total o parcial;

d) Medidas destinadas a impedir los nacimientos en el seno del grupo;

e) Traslado por fuerza de niños del grupo a otro grupo. 
dio mediante la eliminación física de buena parte de la población indígena, ${ }^{4}$ éste continuó bajo la modalidad de someter a los pueblos indígenas a condiciones que casi han provocado su desintegración. De ahí las demandas de los pueblos indígenas que libran una lucha de resistencia respetable. Con todo, los pueblos indígenas en El Salvador subsisten y sus manifestaciones culturales constituyen buena parte de nuestro patrimonio cultural, como las primeras naciones que se asentaron en nuestro territorio. Esto implica que, por un lado, los pueblos indígenas deben ser reconocidos en esta dimensión y en consecuencia, ser objeto del correspondiente respeto; y por el otro, el tema de la cultura ancestral, es cohesionadora de todos los salvadoreños y es por tanto, un elemento de la esencia de nuestro país. Sin embargo, los pueblos indígenas han estado ausentes en las reflexiones de país, pues los salvadoreños negamos o eludimos este tema; pero no podemos continuar de esta forma. Los acontecimientos en los últimos años a partir de los movimientos indígenas y luego los gobiernos en Sudamérica, donde se retoma la sabiduría ancestral como respuesta a problemas actuales, las fallas del sistema neoliberal que implica la búsqueda de otras opciones, la dinámica de la violencia en nuestro país que urge de constante análisis y reflexión y hasta el hecho de que el invierno se vea particularmente trastornado, nos indican que hay que ver hacia nuestros orígenes, porque seguramente nuestros abuelos tienen mucho que decir desde su sabiduría.

La falta de visibilización de los pueblos indígenas ha provocado que no tengamos referencia completa y actualizada de su situación, sin embargo, se tiene alguna información: en el libro, El Perfil de los Pueblos Indígenas de El Salvador ${ }^{5}$, se ha consignado que los pueblos indígenas son más pobres que el promedio de los pobres en nuestro país, pues indica que el $38.3 \%$ de las y los indígenas se calificó en extrema pobreza; el $61.1 \%$ se calificó en la línea de pobreza y sólo el $0.6 \%$ calificó con cobertura de sus condiciones básicas de vida. La mayoría de los indígenas (un 85\% aproximadamente ${ }^{6}$ ) no tienen tierras para cultivar, con lo cual, deben someterse a arrendamientos a veces, leoninos y tienen que comprar los insumos agrícolas con mucho sacrificio. Al visitar a las comunidades indígenas, se evidencia que las artesanías son mal pagadas y por tanto, las ganancias son prácticamente nulas. Pero también es de resaltar la actitud de resistencia de las comunidades indígenas que con su lucha, a pesar de la falta de recursos, se han preservado como tal y en esto han mantenido sus manifestaciones culturales. No obstante, las comunidades indígenas en El Salvador se encuentran en sus últimos momentos. Gran parte de su herencia

4. No se tienen datos exactos pues las cifras varían mucho, según diferentes versiones. Es por esto que es necesario que se esclarezca este y otros tantos hechos de la historia de los pueblos indígenas en El Salvador.

5. Consejo Nacional para la Cultura y el Arte, CONCULTURA. Perfil de los Pueblos Indígenas en El Salvador. (El Salvador, 2003), 33.

6. Federación Luterana Mundial. Informe Sombra de los $9^{\circ}, 10^{\circ}, 11^{\circ}, 12^{\circ}$, y $13^{\circ}$ informes periódicos de la República de El Salvador presentado Ante el Comité para la Eliminación de la Discriminación Racial de la Organización de las Naciones Unidas. (El Salvador, 2006), 18. 
cultural está en abuelos que pasan los sesenta años ${ }^{7}$; no se observa un relevo generacional, pues la juventud y niñez indígena es renuente a sus tradiciones. Esta realidad provoca que, varias instancias del sistema de Naciones Unidas, como el Comité para la Eliminación de la Discriminación Racial de la Organización de las Naciones Unidas (ONU) y el Comité de Derechos Humanos, recomienden de forma insistente el reconocimiento de los derechos de pueblos indígenas y el desarrollo de políticas públicas a su favor. También es por esto que, el Gobierno anterior reconoció ante el referido Comité, que somos un país multicultural y pluriétnico y abrió espacios para los pueblos indígenas en diferentes instancias estatales, que el actual Gobierno consideró en su Plan Quinquenal, el tema de pueblos indígenas como un eje transversal, y que el año recién pasado, se reconociera a los indígenas en el artículo 63 inciso segundo de la Constitución. En este contexto, El Salvador debe plantearse la necesidad de reconocer a los pueblos indígenas con todo lo que esto significa; debe dar ese cambio a favor no sólo de las comunidades indígenas sino a favor de nuestra visión de nación pluricultural y multiétnica.

\section{La Ruta Crítica: desde el derecho colonial hasta el reconocimiento constitucional de los pueblos indígenas}

Todo sistema normativo está llamado a corresponder a una realidad, pero la definición de las normas depende de la correlación de poderes. Al inicio de la colonia, en lo que hoy es nuestro país, la realidad de vencedores y vencidos implicó que las normas estarían definidas por los primeros, en este caso, la Corona española que en un principio, regulaba a través de reales cédulas. Uno de los primeros objetivos fue controlar a los indígenas en reducciones que fueron poblaciones diseñadas por los españoles. En estas reducciones se instauraron las tierras comunales y ejidales:

Al poco tiempo llegó la real cédula del 10 de junio, 1540, y fue terminante: los indios tenían que ser reducidos a poblados, a la fuerza si era necesario. ${ }^{8}$ El nuevo lugar, tanto cuanto se trataba sólo de trazar, como de un radical cambio de sitio, fue escogido por frailes y caciques. Así surgieron poblaciones ordenadas y planificadas, con el patrón urbano que se volvió clásico, como comunidades autárquicas

7. En 2013 el Gobierno de El Salvador otorgó un bono a los nahuablantes mayores de 60 años. Con motivo de esto, el Departamento de Pueblos Indígenas de la Secretaría de Cultura de la Presidencia logró identificar a unos 197 nahuablantes de esa edad. Considerando a las personas nahuablantes menores de 60 años, la cifra total no aumentaría mucho. Es por eso que el idioma náhuat de $\mathrm{El}$ Salvador, está considerado por la UNESCO como un idioma en peligro de extinción.

8. Escalante Arce, Pedro Antonio. Códice Sonsonate, (El Salvador: Dirección de Publicaciones e Impresos, Consejo Nacional para la Cultura y el Arte, Ministerio de Educación,1992), 23, citando a Fuentes y Guzmán, Francisco Antonio. Historia de Guatemala o Recordación Florida, escrita en el siglo XVII por el capitán D. Francisco Fuentes y Guzmán, natural, vecino y regidor perpetuo de la ciudad de Guatemala, que publica por primera vez con notas e ilustraciones D. Justo Zaragoza; edición de Justo Zaragoza. Luis Navarro editor, Madrid. Dos tomos. 1882, parte II, libro VII, Cap. XVI, 326. 
en que seguían jugando papel activo en su administración los viejos señores, ya como alcaldes, ya como gobernadores. A estas reducciones, o pueblos de indios, se les dieron tierras de uso común, en carácter de tierras comunales y ejidales de manera perpetua e inalienable. ${ }^{9}$

Otra medida importante para establecer el sistema colonial, donde se manifestó claramente la lógica de vencedores y vencidos, fue la encomienda, mediante la cual los conquistadores o sus familiares, tenían asignados un grupo de indígenas a su servicio y éstos a su vez, serían evangelizados, convirtiéndose en una manera de esclavizar a los indígenas. Sin embargo por la lucha de defensores como Fray Bartolomé de las Casas, posteriores normativas fueron suprimiendo la institución de las encomiendas. ${ }^{10}$

En general, los indígenas fueron sujetos a normas que tocaban varios aspectos concernientes a su sometimiento a la Corona española y a la Iglesia, lo que incluía también algunas normas que les protegían:

El territorio que hoy conocemos como El Salvador, fue parte de la Monarquía hispánica, durante la era colonial (provincias de San Salvador y Sonsonate). Como parte integrante, quedó sujeto a diversas disposiciones, normativas y leyes que se emitieron desde el siglo XVI. Por ejemplo, las Leyes Nuevas de 1540-1542, por las que los indios fueron reconocidos como vasallos libres, es decir, no esclavos, pero que contribuirían con "cargas económicas" a la Corona (tributos). Las audiencias fueron creadas como órganos de justicia para defender, entre otros asuntos, a los indígenas. Por ello, había un fiscal protector de indios, quien recibía constantemente las representaciones (informes) de quejas de aquellos sobre diversos asuntos. Los concilios realizados en las ciudades de México y Lima -los últimos fueron en el siglo XVIIInormaron de manera eclesiástica a los naturales (enseñanza de doctrina, la lengua en que sería enseñada, extirpación de idolatrías, celebración de festividades, celebraciones permitidas, uso de imágenes, etc.). Sin embargo, fue la Recopilación de leyes de los Reynos de Indias, publicadas a finales del siglo XVII la que aglutinó el conjunto de leyes dictadas hasta ese momento sobre la estructuración del mundo hispano

9. Escalante Arce, Pedro Antonio. Códice Sonsonate. (El Salvador: Dirección de Publicaciones e Impresos, Consejo Nacional para la Cultura y el Arte, Ministerio de Educación,1992), 23.

10. La encomienda era un derecho implantado por España en América para regular las relaciones entre españoles e indígenas. El rey, en compensación por los servicios que el conquistador había prestado a la Corona, le cedía a éste el tributo o servicio personal que el indio debía pagar a cambio de su evangelización. El súbdito español, el encomendero, era, en definitiva, un terrateniente que explotaba a los indios. Las Leyes Nuevas, de 1542, denegaron la concesión de nuevas encomiendas y establecieron que éstas debían volver a la Corona a la muerte del encomendero. A comienzos del siglo XVIII se inició el proceso que llevó a su total supresión. NationalGeographic,España. http:// www.nationalgeographic.com.es/articulo/historia/actualidad/7799/las_leyes_nuevas_alegato_ favor_los_indios.html (consultada el 3 de noviembre de 2015). 
en América, y por supuesto, de los Indígenas. Las leyes posteriores se basaron en estas. ${ }^{11}$

El capítulo VI de la Recopilación de leyes de los Reynos de Indias o Leyes de Indias, en su introducción reza:

Que los Indios sean favorecidos, y amparados por las lusticias Ecleciasticas, y Seculares. Aviendo detratar en este libro la materia de indios su libertad, aumento y alivio como se contiene en los títulos de que se ha formado. Es nuestra voluntad encargar a los Virreyes, Presidentes y Audiencias el cuidado de mirar por ellos, y dar las ordenes convenientes para que sean amparados, favorecidos y sobrellevados por lo que se remedien los daños que padecen y vivan sin molestias ni vejación quedando esto de una vez assentado y teniendo muy presentes las leyes de estas recopilación que les favorecen, amparan y defienden de cualquier agravios, y que las guarden y hagan guardar muy puntualmente castigando con particular y rigurosa demostracion á los transgresores. Y rogamos y encargamos a los Prelados Eclesiasticos, que por su parte lo procuren como verdaderos padres espirituales de esta nueva Christiandad y todos los conserven en sus privilegios, y prerrogativas, y tengan en su protección. ${ }^{12}$

Luego le siguen varias disposiciones, algunas que favorecen a los indígenas pero otras son claramente discriminatorias, como las que prohíben al indígena portar armas o poseer caballos. También las hay de carácter paternalista considerando la vulnerabilidad que los indígenas tenían por una parte, pero también la visión racista vigente en esa época, teniendo a los indígenas como seres inferiores que necesitaban ser regulados, controlados y protegidos. Algunos ejemplos:

Ley XXXVI Que no se pueda vender vino a los Indios. Ordenamos que en los Lugares y pueblos de Indios, no entre vino, ni se les pueda vender, y los Alcaldes mayores y Corregidores no contravengan á las ordenes dadas ni por su cuenta ó interposición de otras personas lo hagan comerciar por el grave daño que resulta a la salud, y conservación de los Indios y los Virreyes y Audiencias castiguen estos excessos, con el rigor, y demostración que conviene. ${ }^{13}$

Ley XXXVIII Que no se consientan bayles a los Indios sin licencia del Gobernador y sean con Templanza y honestidad. No se consientan

11. Consulta directa al Dr. Sajid Herrera, Historiador.

12. Congreso de la República del Perú. Archivo Digital de la Legislación del Perú. Leyes de Indias. http://www.leyes.congreso.gob.pe/Documentos/Leylndia/0206001.pdf (consultada el 17 de septiembre de 2015), Libro VI Título Primero, De los Indios.

13. Congreso de la República del Perú. Archivo Digital de la Legislación del Perú. Leyes de Indias. http://www.leyes.congreso.gob.pe/Documentos/Leylndia/0206001.pdf (consultada el 17 de septiembre de 2015). Libro VI Título Primero, De los Indios, XXXVI. 
bayles públicos y celebridades de los Indios sin licencia del Gobernador, $y$ estos no sean en las estancias, y repartimientos, ni en tiempo de cosechas y en ninguna ocasión se permita que en juntas, y festejos se desconcierten, y destemplen en la bebida, pues se han experimentado muchos excessos y deshonestidades de semejantes juntas. ${ }^{14}$

En la práctica, tanto indígenas como ladinos fueron vulnerables y de ahí el origen de los conflictos sociales donde se incluían los motines y levantamientos:

No se puede obviar que la mayor vulneración tuvieron los ladinos y mulatos, al menos antes de las reformas borbónicas, quienes al no tener cabida en las normativas proteccionistas y paternalistas de las que gozaron los indígenas -aunque ahora nos parezcan colonialistastuvieron que "habérselas" e ingeniárselas para sobrevivir en un mundo por el que quedaron excluidos. No era extraño, entonces, que los ladinos hayan sido los mayores contrabandistas, agentes del abigeato, etc., pues, según los comentarios de la época, vivían "sin ley, sin Rey y sin Dios". De ahí la profusión de levantamientos que ocurrieron no sólo en nuestro país sino en el resto de Centroamérica. Los levantamientos fueron estrategias utilizadas por los indígenas para exigir a la Corona el cumplimiento de su pacto con sus antepasados de protegerlos. Ante el reformismo borbónico, que si bien buscó cortar con la mala influencia de muchos corregidores y alcaldes mayores, impuso una serie de medidas económicas que afectaron a los indígenas. Por ello, resulta muy iluminador las protestas andinas de Tupac Catari y su discurso en contra de los funcionarios del rey, quienes no hacían cumplir los pactos inmemoriales entre su "nación" (los pueblos indígenas) y su monarca. ${ }^{15}$

Posteriormente a la independencia, las leyes especiales para indígenas fueron suprimidas, quedando los pueblos indígenas sin ninguna legislación que los protegiera:

Con la independencia, debido a la herencia del constitucionalismo liberal español (1810-1812; 1820-1821), se dejaron a un lado (o se trató de hacer) las distinciones jerárquicas que habían prevalecido durante el período colonial. ¿Por qué razón? el constitucionalismo liberal hispano había creado en sus dos épocas un régimen ciudadano, buscando homogenizar civilmente a la inmensa mayoría de vasallos (de hecho, quedó suprimido el epíteto de vasallo). Por esa razón, con la independencia y la era republicana, se comenzó a hablar

14. Congreso de la República del Perú. Archivo Digital de la Legislación del Perú. Leyes de Indias. http://www.leyes.congreso.gob.pe/Documentos/Leylndia/0206001.pdf (consultada el 17 de septiembre de 2015), Libro VI Título Primero, De los Indios, XXXVIII.

15. Consulta directa al Dr. Sajid Herrera, Historiador. 
constitucionalmente de ciudadanos, de igualdad ante la ley, etc. Esto implicó, en el caso salvadoreño, una "modernidad política" (como han apuntado historiadores como Francois-Xavier Guerra, Manuel Chust, Javier Fernández Sebastián, Jośe M. Portillo, entre muchos otros) que también tuvo su otra faceta, sus costos, pues si bien se buscó la igualdad civil de todos los habitantes, esa homogenización terminó anulando la diversidad étnico-cultural, pues el proyecto de nación moderna quería a ciudadanos, no a lencas, ladinos, nahuat, etc. Y ello ocurrió, con sus variantes en cada caso, en toda América Latina. El caso más paradigmático fue Guatemala: con el largo gobierno de Rafael Carrera, como una forma de paternalismo caudillismo, revivió las leyes indianas españolas durante su régimen político para proteger a los indígenas. Además hay que considerar que en Guatemala, tanto en el siglo XIX como en la actualidad, el peso de la población indígena fue y sigue siendo muy fuerte; caso diferente al nuestro, en donde los procesos de mestizaje y latinización fueron muy crecientes desde finales del siglo XVIII. Pero tanto en el caso guatemalteco como en el salvadoreño, que privó un proyecto de homogenización civil y ciudadana, los indígenas quedaron desprotegidos, como cualquier ciudadano, al ser suprimidas las audiencias y los fiscales protectores, pues se estaba ante ciudadanos y no ante indígenas, menores de edad. Además, a pesar de la proclamada igualdad, siguieron ocupándose en grandes contingentes para trabajos en las haciendas, a través de formas coercitivas. En el tema indígena la modernidad política tiene su lado positivo (igualdad ante la ley, indígena como ciudadanos, etc.), pero también sus costos (pérdida de la diversidad étnico-cultural). ${ }^{16}$

La desventaja en que quedaron los indígenas después de la colonia, provocó una situación conflictiva:

marginados por las leyes de la colonia e incapaces de imponerse frente a los criollos, los ladinos optaron por asentarse en tierras de indígenas o se dedicaron al comercio y los oficios. En cualquier caso fue fácil que entraran en conflicto con los indígenas. Sin embargo, la independencia implicó cambios importantes y positivos para los ladinos, pues al abolirse las distinciones del Antiguo Régimen y establecerse la igualdad de los individuos bajo la categoría de "ciudadanos" se encontraron dueños de derechos políticos que antes se les había negado. Lógicamente estos grupos tratarían de sacar ventaja de la nueva situación y por supuesto los más afectados por estas iniciativas fueron los indios. De allí que no sea extraño que los conflictos entre ladinos e indígenas aumentaran significativamente en la época independiente, pues para los indios la independencia significó la pérdida del status especial que habían tenido

16. Consulta directa al Dr. Sajid Herrera, Historiador. 
en la colonia. El sector indígena no percibió mejoras inmediatas, pues los derechos de ciudadano no compensaron las variadas e inusuales obligaciones que imponían. ${ }^{17}$

En este contexto, en 1833 ocurrió el levantamiento de los indígenas Nonualcos liderados por Anastasio Aquino. La revuelta se originó a partir de las condiciones insoportables que los indígenas sufrían en aquel lugar que tiene relación con lo apuntado en el párrafo anterior, es decir la ventaja que el ladino tenía en la época post independencia:

Es evidente que el líder nonualco, no estaba interesado en hacer una revolución y que su movimiento era más bien una reacción en contra de los cambios promovidos por los liberales, los cuales trataban de impulsar una serie de medidas, creando nuevos impuestos, trabajo público forzoso y limitaciones a la propiedad comunal de la tierra. En tal sentido resulta muy iluminador el análisis hecho por el cura Navarro, quien fue enviado por el gobierno a tratar de pacificar a los rebeldes. Navarro declara que el mismo Aquino le dijo que "las tierras que araban y sembraban eran de ellos y que los ladinos se las había arrebatado", que además los trataban como bestias, reclutándolos para conducirlos a sus matanzas y carnicerías. Es obvio que Aquino no pretendía tomarse el poder nacional sino revertir una situación que se había vuelto insoportable para los indios; es por eso que se mostraba dispuesto a aceptar las propuestas de paz del gobierno, siempre y cuando se les permitiera quedarse con sus armas y garantizar con ellas sus derechos. ${ }^{18}$

En ese levantamiento, al controlar territorios Anastasio Aquino, decidió emitir su propia normativa a través de decretos: ${ }^{19}$

\section{Decreto a:}

"Anastasio Aquino, Comandante General de las Armas Libertadoras de Santiago Nonualco. En este día he acordado imponer las penas a los delitos que se cometan, y son las siguientes:

17. Hacer Historia en El Salvador. núm. 01 año 01. Revista electrónica de estudios históricos. López Bernal, Carlos Gregorio. El Levantamiento de los Indios Nonualcos en 1832. Hacia una nueva interpretación, 26 https://www.academia.edu/7112047/_El_levantamiento_de_los_indios_nonualcos_en_1832._ Hacia_una_nueva_interpretaci\%C3\%B3n._Hacer_historia_en_El_Salvador._Revista_electr\%C $3 \%$ B3nica_ de_estudios_hist\%C3\%B3ricos_no._1_2008_ (Consultada el 17 de septiembre de 2015), 26.

18. Hacer Historia en El Salvador. Revista electrónica de estudios históricos núm. 01 año 01. López Bernal, Carlos Gregorio. El Levantamiento de los Indios Nonualcos en 1832. Hacia una nueva interpretación, 25.

19. Al revisar las diferentes versiones tanto del Dr. Julio Alberto Domínguez Sosa, como del Dr. Jorge Arias Gómez y otros autores, se notan ciertas diferencias y surgen dudas sobre la fuente estos decretos. Una vez más, esto nos lleva a la necesidad de investigar aun más sobre la historia de los pueblos indígenas de El Salvador. 
$\left.1^{\circ}\right)$ El que matare, pagara una vida con otra;

$2^{\text {a) }}$ El que hiera, se le cortara la mano;

$3^{a}$ ) El que atropellare a las autoridades civiles y jefes militares, será castigado con 10 años de obras públicas;

$4^{\text {a }) ~ L o s ~ q u e ~ a t r o p e l l a r e n ~ a ~ l a s ~ m u j e r e s ~ c a s a d a s ~ o ~ r e c o g i d a s ~ s e r a ́ n ~ c a s t i g a d o s ~ c o n ~ a r r e g l o ~}$ a las leyes;

$\left.5^{\mathrm{a}}\right)$ El que robare, tendrá la pena de cortarle la mano, por primera vez;

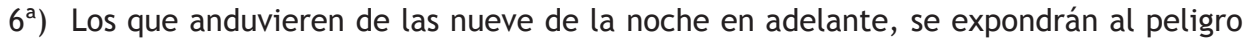
de la muerte; y si se salvaren a pagar su infracción con un año de obras públicas;

$7^{\mathrm{a}}$ ) Los que fabriquen licores, sufrirán multa de cinco pesos por primera vez, y por segunda vez la de diez.

Dado en Tepetitán, el 16 de Febrero de $1833 .^{20}$

\section{Decreto b:}

"Yo, Anastasio Aquino, Comandante General de las Armas Libertadoras de Santiago Nonualco. En este día he acordado lo siguiente: Quedan libres de obligación de pagar todos los deudores que se encontraren en el territorio en que hace sentir su fuerza mi gobierno.

El que intentare cobrar deudas contraídas antes de lo acordado, sufrirá diez años de prisión, que pagara en obras públicas".

Dado en Tepetitán, en la noche del 16 de Febrero de 1833.

\section{Decreto c:}

Mando que: todo indio, todo sanate (esclavo africano) que no someta a mi Ley, ordeno que se mate. ${ }^{2122}$

Se ha cuestionado y comentado sobre estos decretos, en cuanto a su contenido y autenticidad, sin embargo, considerando el dato y los hechos históricos del levantamiento, podemos plantear que, de ser ciertos, estos decretos se derivan de un acto de autonomía en un "territorio en que hace sentir su fuerza" este movimiento. Es por tanto, uno de los pocos momentos en que los indígenas

20. Cevallos, Jose Antonio, “Recuerdos Salvadoreños”, segunda edición, ( Editorial del Ministerio de Educación, San Salvador, 1961), 242 y 243, citado en Arias Gómez, Jorge. Anastasio Aquino, recuerdo, valoración y presencia (Cuadernos de El Socialista Centroamericano Número 19), 38 y 39 http://www.elsoca.org/pdf/esca/Cuaderno\%20Anastasio\%20Aquino.pdf (consultada el 22 de octubre de 2015).

21. Flores Figeac José, “Recordatorio Histórico de la República de El Salvador”, (Talleres Gráficos Cisneros, sin fecha), 105, citado en Arias Gómez, Jorge. Anastasio Aquino, Recuerdo, Valoración y Presencia (Cuadernos de El Socialista Centroamericano Número 19), 39 http://www.elsoca.org/ pdf/esca/Cuaderno\%20Anastasio\%20Aquino.pdf (consultada el 22 de octubre de 2015).

22. Este decreto en particular, ha sido puesto en duda por diferentes autores como el Dr. Julio Alberto Domínguez Sosa en su libro Las tribus nonualcas y su caudillo Anastasio Aquino (Editorial Universitaria Centroamericana, 1984), 114; y el Dr. Jorge Arias Gómez de cuyo libro hemos tomado esta cita. 
logran reivindicarse aunque fuera local y temporalmente, de ahí la importancia de estas normas.

Pero, durante el siglo XIX, las leyes que implicaron un punto de inflexión, fueron las que extinguieron las tierras ejidales y comunales que fueron instituidas durante los primeros años de la colonia como parte de la planificación de los pueblos de indígenas donde éstos habían sido concentrados. El perjuicio fue profundo hacia las comunidades indígenas. La Ley de Extinción de Comunidades de 1881 en sus considerandos argumenta:

Que la indivisión de los terrenos poseídos por comunidades impide el desarrollo de la Agricultura, entorpece la circulación de la riqueza y debilita los lazos de la familia y la independencia del individuo.

Y prescribe:

Art. $1^{\circ}$. Losterrenos llamadoscomunalesserándivididosentre loscondueños aprorratadelasumaconquecadaunohubierecontribuidoparasuadquisición, y a falta de este dato la división se hará por cabezas equitativamente. ${ }^{23}$

La extinción de las tierras ejidales y comunales se ha tenido como una de las causas que llevaron al levantamiento indígena de 1932. Con motivo de este levantamiento, que tuvo como respuesta una cruel represión estatal, hubo un decreto de amnistía que evidentemente favorecía más a los autores del genocidio que a los participantes del levantamiento:

Art. $1^{\circ}$. Se concede amplia e incondicional amnistía a favor de las personas hubieren participado en la rebelión comunista, de los días veintidós y veintitrés de enero próximo pasado, en los departamentos de San Salvador, La Libertad, Sonsonate o Ahuachapán o en otras poblaciones; quedando exceptuados los individuos que aparecieren culpables de los delitos de asesinato, homicidio, robo, violaciones y lesiones graves.

Art. $2^{\circ}$. Así mismo, se concede amplia e incondicional amnistía a los funcionarios, autoridades, empleados, agentes de la autoridad y cualquier otra persona civil o militar, que de alguna manera aparezcan ser responsables de infracciones a las leyes, puedan conceptuarse como delitos de cualquier naturaleza, al proceder en todo el país, al

23. Corte Suprema de Justicia, Biblioteca Judicial Dr. Ricardo Gallardo, Universidad de El Salvador, Facultad de Jurisprudencia y Ciencias Sociales, Breves Consideraciones al Régimen de Titulación de Inmuebles en la Legislación Salvadoreña, Tesis Doctoral presentada por Horacio José Olmedo Lope, 1969 http://www.csj.gob.sv/BVirtual.nsf/3db6532d39e032fd06256b3e006d8a73/d15682921641b25 306256b3e00747a4d?OpenDocumentLey de Extinción de Comunidades del 23 de febrero de 1881 (consultada el 17 de septiembre de 2015). 
restablecimiento del orden, represión, persecución, castigo y captura de los sindicados en el delito de rebelión antes mencionado. ${ }^{24}$

Luego del genocidio, el Gobierno se ocupó del tema de los pueblos indígenas seguramente para ejercer un mayor control de éstos:

los hechos más contradictorios de las políticas de la década de 1930 es que, después de la represión de que fueron objeto los pueblos indígenas del occidente de El Salvador por parte del ejercito, tras el levantamiento de 1932, inmediatamente concluidas las operaciones militares, el gobierno restableció las antiguas formas de interacción con las comunidades indígenas, además de interesarse en la protección de los sobrevivientes de la masacre (Alvarenga, 2004:375-376). ${ }^{25}$ En este sentido, el gobierno de Maximiliano Hernández Martínez pretendía constituir una política que regía las relaciones con los grupos subalternos, buscaba cimentar su hegemonía en la justicia ofreciendo a los grupos subalternos la intervención del Estado y su protección cuando los poderosos transgredieran los límites de la legitimidad (Urbina, 2007: 43) ${ }^{26}$. En este caso, cuando los ladinos, los militares o cualquier otro grupo o persona se quisieran sobrepasar con los indígenas. ${ }^{27}$

Durante el gobierno del General Maximiliano Hernández Martínez, curiosamente El Salvador participó en el Primer Congreso Indigenista Interamericano en abril de 1940, ratificó la Convención Internacional Relativa a los Congresos Indigenistas Interamericanos y al Instituto Indigenista Interamericano (Convención de Patzcuaro), y fundó un Instituto Indigenista Nacional ${ }^{28}$. Uno de los principales fines de esta Convención era el apoyar políticas indigenistas según la exposición de motivos en su parte introductoria:

Los Gobiernos de las Repúblicas Americanas, animados por el deseo de crear instrumentos eficaces de colaboración para la resolución de sus problemas comunes, y reconociendo que el problema indígena atañe a toda América; que conviene dilucidarlo y resolverlo y que

24. Decreto 121 (El Salvador Asamblea Legislativa de la República de El Salvador, 11 de julio de 1932), artículos 1 y 2.

25. Marielba Herrera y Herbert Erquicia. Aproximación Etnográfica al Culto Popular del Hermano Macario en Izalco, Sonsonate. (El Salvador. Universidad Tecnológica, 2010), 37, citando a ALVARENGA, Patricia (2006). Cultura y ética de la violencia. El Salvador 1880-1932. 2da. Edición, San Salvador, El Salvador. Dirección de Publicaciones e Impresos. Biblioteca de Historia Salvadoreña, Vol. 19, 375-376. 26. Marielba Herrera y Herbert Erquicia. Aproximación Etnográfica al Culto Popular del Hermano Macario en Izalco, Sonsonate. (El Salvador. Universidad Tecnológica, 2010), 37, citando a URBINA Gaitán, Chester (2005). Poder-Saber y Estado en El Salvador (1931-1944). En: Revista Cultura, No. 96, Mayo-Agosto, 43.

27. Marielba Herrera y Herbert Erquicia. Aproximación Etnográfica al Culto Popular del Hermano Macario en Izalco, Sonsonate. (El Salvador. Universidad Tecnológica, 2010), 37.

28. El Instituto Indigenista Interamericano: Sus actividades en el período 1943-1945 http://www. jstor.org/stable/40977597?seq=1\#page_scan_tab_contents (consultada el 13 de octubre de 2015). 
presenta en muchos de los países americanos modalidades semejantes y comparables; reconociendo, además, que es conveniente aclarar, estimular y coordinar la política indigenista de los diversos países, entendida esta como conjunto de desiderata, de normas y de medidas que deban aplicarse para mejorar de manera integral la vida de los grupos indígenas de América... ${ }^{29}$

Sin embargo, el antropólogo Alejandro Dagoberto Marroquín se refiere a este evento como un recurso utilizado para mantener una apariencia:

En 1932, el tirano Hernández Martínez ordenó la muerte de más de 20,000 indígenas del Occidente de la República; más tarde, en 1940, envió a su Ministro de Educación, como representante de El Salvador al Primer Congreso Indigenista Interamericano en Pátzcuaro e inmediatamente se apresuró a suscribir y ratificar la Convención Internacional que creó el Instituto Indigenista Interamericano. El Salvador es pues, fundador de ese Instituto. Además creó una ley creando el Instituto Indigenista Salvadoreño. El dictador quería presentar ante el mundo la imagen de un estadista preocupado por la causa indigenista y no la de un "asesino de indios" como se le solía llamar en los círculos clandestinos de la resistencia. Pero el indigenismo de Hernández Martínez fue indigenista de exportación; se afilió al Instituto Indigenista Interamericano y dictó la ley del Instituto filial; pero dentro del país no se hizo ninguna política indigenista positiva; no se concretó en realidad la ley que creó el Instituto Indigenista Salvadoreño. Es durante este período que el indio se esfuma en las estadísticas. Desaparece el Instituto de Indígenas de Nahuizalco y oficialmente no se realiza ninguna política de promoción social dirigida especialmente a los grupos indígenas. Era como si en El Salvador no tuviéramos problemas indígenas. ${ }^{30}$

Por todo esto, los indígenas permanecieron entre la invisibilización y un perfil bajo. Hacia fines de la década del 50, un avance importante fue la ratificación por el Estado salvadoreño, del Convenio sobre Poblaciones Indígenas y Tribales en Países Independientes 107 de la Organización Internacional del Trabajo (OIT), el 18 de noviembre de 1958. Dicho Convenio, si bien prescribe algunos derechos de los pueblos indígenas, ha quedado ampliamente superado, habida cuenta de que, en aquel momento, se conceptualizaba a los pueblos indígenas como pueblos "atrasados" a los que había que dirigir en su destino hacia la asimilación en la sociedad.

29. Convención Internacional Relativa a los Congresos Indigenistas Interamericanos y al Instituto Indigenista Interamericano http://proteo2.sre.gob.mx/tratados/ARCHIVOS/I.I.I.pdf (consultada el 13 de octubre de 2015).

30. Marroquín, Alejandro Dagoberto. “El Problema Indígena en El Salvador”. América Indígena, año XXXV núm. 4. (México Octubre- diciembre de 1975), 767. 
Durante el conflicto armado 1980-1992, los pueblos indígenas fueron una vez más victimizados. Dos de las expresiones de esto fueron las masacres del cantón Carrizal de Nahuizalco, el 13 de julio de 1980 y la masacre de Las Hojas, San Antonio del Monte, el 22 de febrero de 1983 ambas en el departamento de Sonsonate. De esta última, hubo una resolución de la Comisión Interamericana de Derechos Humanos. En los Acuerdos de Paz (1992) el tema de reconocimiento de pueblos indígenas no se visibilizó como sucedió en su momento, en los Acuerdos de Paz de Guatemala, ya que, en ese país se consideró como algo fundamental. ${ }^{31}$ Del período de post guerra (1994) data la ratificación el Convenio Constitutivo del Fondo para el Desarrollo de los Pueblos Indígenas de América Latina y el Caribe ratificado por El Salvador. ${ }^{32}$ Sin embargo, al igual que el Instituto Indigenista Interamericano, la acción del Fondo Indígena en el país ha sido limitada posiblemente por la tendencia de los diferentes gobiernos de derecha, de invisibilizar a los pueblos indígenas tal y como se ha apuntado.

En septiembre de 2007, El Salvador votó a favor de la Declaración de Naciones Unidas Sobre los Derechos de los Pueblos Indígenas. En esta declaración, se consignan importantes derechos que constituyen un avance importante en los derechos indígenas:

\section{Artículo 1}

Los indígenas tienen derecho, como pueblos o como individuos, al disfrute pleno de todos los derechos humanos y las libertades fundamentales reconocidos en la Carta de las Naciones Unidas, la Declaración Universal de Derechos Humanos y las normas internacionales de derechos humanos.

\section{Artículo 11}

1. Los pueblos indígenas tienen derecho a practicar y revitalizar sus tradiciones y costumbres culturales. Ello incluye el derecho a mantener, proteger y desarrollar las manifestaciones pasadas, presentes y futuras de sus culturas, como lugares arqueológicos e históricos, objetos, diseños, ceremonias, tecnologías, artes visuales e interpretativas y literaturas.

2. Los Estados proporcionarán reparación por medio de mecanismos eficaces, que podrán incluir la restitución, establecidos conjuntamente con los pueblos indígenas, respecto de los bienes culturales intelectuales, religiosos y espirituales de que hayan sido privados sin su consentimiento libre, previo e informado o en violación de sus leyes, tradiciones y costumbres.

31. Como parte de los Acuerdos de Paz entre el Gobierno de Guatemala y la Unidad Revolucionaria Nacional Guatemalteca, (URNG) se generó el Acuerdo sobre Identidad y Derechos de los Pueblos Indígenas en marzo de 1995.

32. Ratificado mediante Decreto Legislativo No. 68 del 14 de julio de 1994, Diario Oficial No. 155, Tomo 324 del 24 de agosto de 1994. 


\section{Artículo 19}

Los Estados celebrarán consultas y cooperarán de buena fe con los pueblos indígenas interesados por medio de sus instituciones representativas antes de adoptar y aplicar medidas legislativas o administrativas que los afecten, a fin de obtener su consentimiento libre, previo e informado. ${ }^{33}$

Aun cuando es un hecho notable y muy positivo, hay que tener en cuenta que esta Declaración por su carácter no vinculante en sentido jurídico, tendrá fuerza cuando se invoque en los procesos de defensa de los derechos de los pueblos indígenas. Como algo paradójico, en 2007 se realizó un censo poblacional que arrojó poco más de 13,000 indígenas en El Salvador, ante lo cual, los pueblos indígenas interpusieron varias demandas de amparo que fueron declaradas no admisibles en su momento. El Comité para la Eliminación de la Discriminación Racial se pronunció sobre el censo:

El Comité expresa su grave preocupación por las notables diferencias existentes en las cifras relativas a la composición étnica del país derivadas de los resultados del VI Censo de Población y V de Vivienda, realizados en 2007, y de otras fuentes fidedignas. Sin embargo, también toma nota de la posición expresada por el Estado parte en su presentación ante el Comité, que disipa sus preocupaciones sobre los resultados de esos censos. El Comité señala la intención del Estado parte de realizar un nuevo censo en 2012. ${ }^{34}$

De igual forma, el Dr. James Anaya, en su momento se refirió al tema:

Los pueblos indígenas de El Salvador incluyen los pueblos náhuas, pipiles, lencas, kakawiras, y maya chortí. Según el censo de 2007 realizado por la Dirección General de Estadística y Censos, hay 13.319 personas indígenas en El Salvador, lo que representa aproximadamente el $0,2 \%$ de la población total del país. De ellos, el $15 \%$ se identificó como lenca, el $31 \%$ se identificó como kakawira, el $27 \%$ se identificó como pipil, y el $27 \%$ se identificó como “otro". Sin embargo, el censo de 2007 ha sido ampliamente criticado por subestimar significativamente la población indígena en El Salvador y por distorsionar el desglose de las etnias indígenas. La cantidad y calidad de las preguntas planteadas por el censo son citadas frecuentemente como factores contribuyentes a su inexactitud. En este sentido, otras estimaciones indican que la población indígena del país se encuentra entre el $10 \%$ y el $12 \%$ de la población total. ${ }^{35}$

33. Declaración de las Naciones Unidas sobre los Derechos de los Pueblos Indígenas ( Organización de las Naciones Unidas, 2007) artículos 1,11 y 19.

34. Comité para la Eliminación de la Discriminación Racial de la Organización de las Naciones Unidas. Examen de los Informes Presentados por los Estados Partes de conformidad con el artículo 9 de la Convención. Observaciones finales del Comité para la Eliminación de la Discriminación Racial, El Salvador. ONU, 2010 (CERD/C/SLV/14-15), 2.

35. Informe del Relator Especial sobre los Derechos de los Pueblos Indígenas, James Anaya, sobre la 
Parte del reconocimiento a los pueblos indígenas, será realizar un censo tal y como lo ha recomendado el Comité para la Eliminación de la Discriminación Racial en el informe de 2010 y bajo la consulta y participación de las comunidades indígenas.

Como se ha apuntado, con el primer gobierno del FMLN, en agosto de 2010 El Salvador reconoció ante el Comité para la Eliminación de la Discriminación Racial de la ONU, que somos un país multicultural y pluriétnico, dándose apertura mayor para los pueblos indígenas. Luego de este reconocimiento, un punto de inflexión ha sido la reforma del Art. 63 de la Constitución: ${ }^{36}$

El Salvador reconoce e a los pueblos indígenas y adoptará políticas a fin de mantener y desarrollar su identidad étnica y cultural, cosmovisión, valores y espiritualidad.

Esta disposición transforma a El Salvador en un estado multicultural y pluriétnico, por cuanto este principio da pie a legislar a favor de los pueblos indígenas del país. Aparte de esto, refuerza la Declaración de las Naciones Unidas sobre los Derechos de los Pueblos Indígenas y puede ser una base para la firma y ratificación del Convenio 169 de la OIT.

Sin embargo, el artículo en cuestión, por su ubicación (Régimen de Derechos Culturales) y por su alcance, se puede quedar corto, pues se circunscribe a la “identidad étnica y cultural, cosmovisión, valores y espiritualidad “ de los pueblos indígenas; pero teniendo en cuenta que, en temas de derechos humanos, las normas deben interpretarse en el sentido más amplio posible, el artículo en cuestión puede abarcar muchos aspectos más. Esto dependerá tanto de la legislación secundaria y de las políticas públicas que se desarrollen en virtud de esta importante reforma. Existen por otra parte, algunas disposiciones dispersas en diferentes cuerpos legales como el art. $62^{37}$ en la Constitución de la República que establece la obligación estatal de promover la conservación de las “lenguas ancestrales”. También la Convención de los Derechos del Niño, posee una disposición (art. $30^{38}$ ) concerniente a los derechos de la niñez indígena y el

\footnotetext{
situación de los pueblos indígenas en El Salvador. (Ginebra, 25.06.2013) 4, 5.

36. Decreto Legislativo del 12 de junio de 2014.

37. Art. 62.- El idioma oficial de El Salvador es el castellano. El gobierno está obligado a velar por su conservación y enseñanza. Las lenguas autóctonas que se hablan en el territorio nacional forman parte del patrimonio cultural y serán objeto de preservación,difusión y respeto. Las lenguas autóctonas que se hablan en el territorio nacional forman parte del patrimonio cultural y serán objeto de preservación, difusión y respeto.

38. Art. 30.- En los Estados en que existan minorías étnicas, religiosas o lingüísticas o personas de origen indígena, no se negará a un niño que pertenezca a tales minorías o que sea indígena el derecho que le corresponde, en común con los demás miembros de su grupo, a tener su propia vida cultural, a profesar y practicar su propia religión, o a emplear su propio idioma.
} 
Convenio sobre Diversidad Biológica que en su Art. 8. ${ }^{39} 40$ prescribe la protección de los saberes de las comunidades indígenas vinculadas a la diversidad biológica. Sin embargo, en la actualidad no hay una legislación secundaria que regule específicamente, los derechos de los pueblos indígenas.

\section{Desarrollando el poder local: Las Ordenanzas de Derechos Indígenas}

A inicios de 2008 acompañé el esfuerzo de los líderes indígenas de Nahuizalco, Sonsonate, con el apoyo de la alcaldía del municipio, en la elaboración de una ordenanza municipal que recogiera los derechos de los pueblos indígenas. Esta normativa sería la primera (aun cuando fuese de carácter local) en mucho tiempo, realizada en conjunto con las comunidades indígenas de ese lugar. La idea surgió ante el hecho de que El Salvador en 2007 votara a favor de la Declaración de las Naciones Unidas sobre los Derechos de los pueblos Indígenas y que había que promover este importante avance en los derechos indígenas. Se trata pues, de que la ordenanza tuviera por una parte, los estándares de la Declaración aludida pero también las propuestas de estas comunidades, que participaron con mucha proactividad en la referida consulta. Este proceso no ha sido fácil y ha presentado obstáculos debido a las tensiones naturales al tema que no se hicieron esperar, pues no hay que perder de vista que lo sucedido en 1932 está aún vigente en esta zona y que se trata de un país que tiene una visión monocultural. La ordenanza de Nahuizalco fue publicada el 6 de julio de 2011; 41 luego le siguieron las alcaldías de Izalco, ${ }^{42}$ Panchimalco ${ }^{43}$ y Cuisnahuat. ${ }^{44}$ En el preámbulo de estas ordenanzas se retoma el carácter reivindicativo de las mismas:

Retomando el aliento de nuestros antepasados y antepasadas desde nuestra historia milenaria de peregrinaje haciendo frente a todo tipo de adversidades y nuestra resistencia desde la época de la colonia hasta nuestros días; herencia que nos afirma como pueblos decididos a luchar por la vida y por nuestra Madre Tierra.

El objeto de esta legislación queda en evidencia en el artículo 1:45

\section{Art. 1. La presente ordenanza tiene por objeto promover el desarrollo}

39. Art. 8..- Con arreglo a su legislación nacional, respetará, preservará y mantendrá los conocimientos, las innovaciones y las prácticas de las comunidades indígenas y locales que entrañen estilos tradicionales de vida pertinentes para la conservación y utilización sostenible de la diversidad biológica y promoverá su aplicación más amplia, con la aprobación y la participación de quienes posean esos conocimientos, innovaciones y prácticas y fomentará que los beneficios derivados de la utilización de esos conocimientos, innovaciones y prácticas se compartan equitativamente.

40. Este artículo se relaciona con el Protocolo de Nagoya sobre el Acceso a los Recursos Genéticos y participación justa y equitativa en los beneficios que se deriven de su utilización al Convenio sobre Diversidad Biológica que El Salvador ha firmado pero aún no lo ha ratificado.

41. Decreto No 1, Publicado en el Diario Oficial del 6 de julio de 2011, tomo 392, número 126, Pág. 11. 42. Decreto No 2, Publicado en el Diario Oficial del 25 de abril de 2012, Tomo 395, número 75, Pág. 57. 43. Decreto No 2, Publicado en el Diario Oficial del 8 de abril de 2015, tomo 407, Número 61, Pág. 148. 44. Decreto No 5, Publicado en el Diario Oficial el 6 de mayo de 2015 tomo 407, número 80, Pág. 23. 45.En la Ordenanza de Panchimalco, este artículo es el art. 3. 
integral en lo económico, social, cultural, y participación efectiva en el ejercicio de los derechos civiles y políticos de las comunidades indígenas del municipio de Nahuizalco lo que incluye la protección y preservación de su propia cultura, de su tierra y territorio, y especialmente de los recursos naturales renovables y no renovables, que constituyen el entorno ecológico de dichas comunidades.

También en los artículos, se recogen los derechos culturales:

Art. 8. Los comunidad indígena tiene derecho a practicar y revitalizar sus tradiciones y costumbres culturales. Ello incluye el derecho a mantener, proteger y desarrollar las manifestaciones pasadas, presentes y futuras de su cultura, como el idioma nahuat, lugares arqueológicos e históricos, utensilios, documentos, diseños, ceremonias, tecnologías, artes visuales e interpretativas y literaturas.

Y los de grupos especiales dentro de los pueblos indígenas como los derechos de la mujer indígena:

Derechos de la mujer indígena

Art. 20. Siendo que la tierra es femenina y nuestra cosmovisión está muy vinculada al nacimiento de la vida a partir de la Madre Tierra, consideramos que la mujer en general y en especial la mujer indígena, es la expresión humana de nuestra Madre Tierra. Aparte de esto, la mujer indígena de debe ser especialmente protegida contra toda forma de discriminación, por tanto, debe ser considerada en esta condición de representante de nuestra Madre Primigenia. La Municipalidad promoverá políticas públicas locales para garantizar los derechos individuales y sociales de la mujer indígena, especialmente en lo concerniente a sus derechos sexuales y reproductivos de acuerdo a su cosmovisión de vida y la conservación de la salud.

Las Ordenanzas Municipales también establecen el derecho a la consulta libre, previa e informada:

Art. 23. Toda actividad, programa, empresa o proyecto que estén relacionadas con la tierra, territorio, los recursos naturales y el medioambiente de la comunidad indígena y en general, toda actividad que afecte los intereses legítimos de la comunidad indígena, debe ser previamente consultada a éstas a través de sus representantes constituidos de acuerdo a sus formas propias de organización.

Las ordenanzas municipales de derechos indígenas retoman los principios de la Declaración de las Naciones Unidas sobre los Derechos de los Pueblos Indígenas, permiten a las comunidades indígenas, incidir en su propia legislación y son 
una herramienta que puede servir para desarrollar los derechos económicos, sociales, culturales y medioambientales para estas comunidades.

\section{El Convenio 169 de la OIT}

A partir del cuestionamiento hacia el Convenio 107 de la OIT, se comenzó a plantear un nuevo instrumento que recogiera de forma más apropiada el concepto actual de los derechos de los pueblos indígenas. El producto de esta larga discusión, es el Convenio 169 Sobre Pueblos Indígenas y Tribales en Países Independientes de la OIT, que fue adoptado por el pleno de la Conferencia General de la OIT en 1989, entrando en vigencia en 1991, luego de la ratificación de dos estados tal como lo requería el texto del mismo. ${ }^{46} \mathrm{~A}$ la fecha, ha sido ratificado por 22 estados, 15 de ellos de América Latina. Actualmente, este Convenio ha sido uno de los temas principales del movimiento indígena de $\mathrm{El}$ Salvador y también varias instancias del sistema de la $\mathrm{ONU}^{47}$ han recomendado a El Salvador su firma y ratificación. Por ahora, el Convenio se encuentra en estudio por parte del Gobierno ya que se requiere de varias medidas en caso de que este Convenio se convierta en ley. Desde luego, la ratificación de este instrumento dependerá de la Asamblea Legislativa.

La importancia del Convenio 169 de la OIT, estriba en que prescribe varios derechos fundamentales como el derecho a la no discriminación, los derechos económicos sociales y culturales y el derecho a la decidir sobre sus prioridades como pueblos:

\section{Artículo 2}

1. Los gobiernos deberán asumir la responsabilidad de desarrollar, con la participación de los pueblos interesados, una acción coordinada y sistemática con miras a proteger los derechos de esos pueblos y a garantizar el respeto de su integridad.

2. Esta acción deberá incluir medidas:

a) que aseguren a los miembros de dichos pueblos gozar, en pie de igualdad, de los derechos y oportunidades que la legislación nacional otorga a los demás miembros de la población;

b) que promuevan la plena efectividad de los derechos sociales, económicos y culturales de esos pueblos, respetando su identidad social y cultural, sus costumbres y tradiciones, y sus instituciones;

c) que ayuden a los miembros de los pueblos interesados a eliminar las diferencias socioeconómicas que puedan existir entre los miembros indígenas y los demás miembros de la comunidad nacional, de una manera compatible con sus aspiraciones y formas de vida.

46. Los países en mención fueron Noruega y México.

47. Tanto el Comité para la Eliminación de la Discriminación Racial, el Comité de Derechos Humanos y el Grupo de Trabajo sobre el Examen Periódico Universal han recomendado la firma y ratificación del Convenio 169 de la OIT al Estado salvadoreño en diferentes recomendaciones. 


\section{Artículo 7}

1. Los pueblos interesados deberán tener el derecho de decidir sus propias prioridades en lo que atañe al proceso de desarrollo, en la medida en que éste afecte a sus vidas, creencias, instituciones y bienestar espiritual y a las tierras que ocupan o utilizan de alguna manera, y de controlar, en la medida de lo posible, su propio desarrollo económico, social y cultural. Además, dichos pueblos deberán participar en la formulación, aplicación y evaluación de los planes y programas de desarrollo nacional y regional susceptibles de afectarles directamente.

Breve referencia de la discusión sobre la viabilidad del Convenio 169 de la OIT El Convenio 169 de la OIT ha provocado grandes discusiones ante una posible firma y ratificación. Los argumentos giran alrededor de dos aspectos: la supuesta inconstitucionalidad del Convenio 169 y el tema del derecho a las tierras de los pueblos indígenas. Con el primer planteamiento, se afirma que el Convenio otorga "privilegios" a los indígenas sobre la generalidad de la ciudadanía, lesionando el derecho a la igualdad prescrito en la Constitución. Hay que tener en cuenta que, si se legisla a favor de grupos humanos específicos es porque éstos lo necesitan dadas sus condiciones particulares de vulnerabilidad (niñez, discapacitados, adultos mayores etc.). En este caso, se trata de una discriminación en positivo. Si el Convenio 169 prescribe condiciones ventajosas en materia de derechos, esto es para compensar la vulnerabilidad aludida y tomar en cuenta la cultura de los pueblos indígenas respecto al resto de la ciudadanía. En todo caso, la reciente reforma constitucional del Art. 63 donde se reconoce a los pueblos indígenas, da sustento al Convenio 169 de la OIT. Con respecto al tema de las tierras, si bien el Art. 14 del Convenio establece el derecho de los pueblos indígenas a las tierras "que tradicionalmente ocupan" se debe tener en cuenta lo que dicta el artículo 14.3 del mismo Convenio: “deberán instituirse procedimientos adecuados en el marco del sistema jurídico nacional para solucionar las reivindicaciones de tierras formuladas por los pueblos indígenas" 48 por tanto, se trata de crear estos procedimientos y la normativa necesaria en armonía con nuestro marco legal y la realidad de nuestro país. Todo esto, en consulta con los pueblos indígenas para la mejor implementación del Convenio 169. También es importante preparar a las organizaciones indígenas y darles a conocer los verdaderos alcances de este instrumento para no generar falsas expectativas.

Más allá de la discusión, no hay que perder de vista que el Convenio 169 de la OIT establecería un estándar importante para los derechos de los pueblos indígenas. Esta normativa se puede traducir en políticas públicas y programas que orienten este proceso para el presente y los próximos gobiernos. 
El Futuro: Hacia la política Nacional de Pueblos Indígenas y la Política de Salud Intercultural

Durante 2013, a iniciativa de líderes indígenas de 18 organizaciones indígenas y 9 instancias estatales, integrantes de la Instancia Multisectorial, ${ }^{49}$ comenzaron con el arduo trabajo de construcción de una propuesta de política nacional de pueblos indígenas. Luego de prácticamente dos años de discusiones, se tuvo como producto una propuesta de política nacional de pueblos indígenas, por tanto, es importante hacer referencia de la información básica de este documento:

El objetivo de la política es:

"Realizar una gestión pública estatal hacia y con los pueblos indígenas, basada en sus derechos y cosmovisión a través de la acción social transformadora". ${ }^{50}$ Para esto se han definido cinco estrategias con sus respectivos objetivos:

\section{Estrategia de Desarrollo Social}

Contribuir al mejoramiento de las condiciones de vida de los pueblos indígenas, mediante el impulso de acciones afirmativas relacionadas con educación, salud, alternativas de habitabilidad, vivienda, vías de acceso y servicios básicos. Se busca así promover el desarrollo integral desde un enfoque con identidad ancestral.

\section{Estrategia de Desarrollo Económico}

Contribuir al mejoramiento de la calidad de vida de los pueblos indígenas, mediante el impulso de acciones económicas orientadas a la obtención de ingreso, empleo digno y formación laboral, desde una perspectiva de desarrollo local intercultural y con base en la forma de ser y pensar de los pueblos originarios.

\section{Estrategia de Desarrollo Cultural}

Fortalecer la identidad de los pueblos indígenas, mediante el impulso de acciones que propicien la protección, reconstrucción, promoción y difusión de las manifestaciones de la cultura indígena.

\section{Estrategia de Sostenibilidad Medioambiental}

Desarrollar las condiciones de sostenibilidad y sustentabilidad medioambiental en los lugares donde habitan los pueblos indígenas, mediante el impulso de acciones que faciliten el uso adecuado de los recursos naturales del entorno de manera simbiótica, desde el enfoque de la preservación y renovación de los mismos y el fortalecimiento de las capacidades de resiliencia.

49. Espacio creado por el Departamento de Pueblos Indígenas de la Secretaría de Cultura de la Presidencia en 2011, como un punto de encuentro entre las organizaciones y comunidades indígenas y las instancias gubernamentales. En este espacio, las organizaciones indígenas se reúnen periódicamente para coordinar diferentes temas con el Gobierno.

50. Secretaría de Cultura de la Presidencia. Propuesta de Política Pública para los Pueblos Indígenas de El Salvador (El Salvador: Secretaría de Cultura de la Presidencia, 2015), 20. 


\section{Estrategia de Gestión Gubernamental}

Impulsar el enfoque intercultural en la gestión gubernamental mediante la representación de los pueblos indígenas tanto desde la sociedad civil como en las estructuras estatales; el desarrollo de acciones que visibilicen a los pueblos indígenas; el reconocimiento de sus derechos; y la defensa y promoción de los derechos de la mujer indígena. ${ }^{51}$

Otro esfuerzo importante, es el del Ministerio de Salud que desde 2012, inició con la Secretaría de Cultura, la Organización Panamericana de la Salud, la Cooperación Brasileña y el Consejo Coordinador Nacional Indígena Salvadoreño (CCNIS), para formular una política de salud intercultural. Este trabajo ha sido desarrollado también a partir de la construcción conjunta con los actores y las consultas a las comunidades indígenas. El objetivo de esta política es:

Incorporar el enfoque intercultural con énfasis de los pueblos indígenas en el Sistema Nacional de Salud que garantice el derecho a la salud, en el marco de la promoción, educación, prevención, atención y rehabilitación en salud, valorizando y armonizando los conocimientos y saberes ancestrales de una forma efectiva, eficiente, con calidad y calidez. ${ }^{52}$

\section{Esta propuesta tiene seis objetivos:}

1) Fortalecer el conocimiento de la cosmovisión de los Pueblos Indígenas en el Sistema Nacional de Salud incorporando los saberes ancestrales, tomando en cuenta el marco jurídico nacional e internacional sobre derechos de pueblos indígenas para realizar el abordaje intercultural.

2) Capacitar al recurso humano prestador de servicios de salud, del Sistema Nacional de salud y de los servidores de salud indígenas en el enfoque intercultural con el fin de armonizar los conocimientos y saberes de ambos sistemas.

3) Disminuir las barreras económicas, geográficas y culturales que afectan el acceso de los pueblos indígenas a la información, educación y atención en el Sistema Nacional de Salud.

4) Integrar el enfoque de salud intercultural como eje transversal de promoción, prevención y atención en salud respetando principios, valores, conocimientos y saberes de los pueblos indígenas.

5) Integrar en el Sistema Único de Información en Salud, en adelante SUIS las variables relacionadas con la situación y salud de los pueblos indígenas.

6) Incluir en la agenda nacional de investigación el tema de salud intercultural. ${ }^{53}$

51. Secretaría de Cultura de la Presidencia. Propuesta de Política Pública para los Pueblos Indígenas de El Salvador. 20, 21.

52. Ministerio de Salud. Propuesta de Política Nacional de Salud Intercultural (El Salvador: Ministerio de Salud, 2015) Documento para Consulta Pública sin numeración de página.

53. Ministerio de Salud. Propuesta de Política Nacional de Salud Intercultural. Documento para Consulta Pública sin numeración de página. 
Ambas propuestas se encuentran en sus correspondientes procesos, para su oportuno lanzamiento. Estos esfuerzos son un paso importante que corresponden al mandato constitucional del inciso segundo del art. 63 de la Constitución que prescribe el deber estatal de adoptar "políticas públicas a fin de mantener y desarrollar su identidad étnica y cultural, cosmovisión, valores y espiritualidad”. Son necesarios procesos sostenidos que vayan incidiendo de manera positiva en la realidad de los pueblos indígenas; es por eso que las políticas públicas, serán un salto cualitativo sumamente sustancial que nos colocará a la cabeza en el avance de los derechos de los pueblos indígenas.

\section{Reflexiones finales}

I. Al examinar los diferentes momentos de la historia conocida de los pueblos indígenas, vemos una resistencia constante; en nuestro país se registran más de 40 levantamientos indígenas ${ }^{54}$ y hay referencia de otras formas de lucha utilizando las normas y las instancias coloniales por ejemplo. Es la lucha del reconocimiento contra la negación. Por tanto es un tema radical, pues en la negación del indígena, con sus antepasados derrotados militarmente en la conquista, con su relegamiento a la servidumbre y esclavitud, con su cultura vista con desprecio, está la base, el origen del poder de facto y político. Como la correlación de poder ha sido desventajosa, el reconocimiento ha dependido de los poderosos y sus intereses. Hemos ido de normativas proteccionistas, hasta leyes que despojaron a los indígenas de sus tierras y una amnistía que perdonó el genocidio. Acaso la resistencia de los pueblos indígenas ha servido para configurar una lucha de dignidad y para mantener sus tradiciones, pero no ha incidido mucho en el reconocimiento. En el momento en que la correlación de vencedores y vencidos ha comenzado a cambiar, se observan también las consecuencias hacia favorecer este reconocimiento y eso ha sucedido hasta el primer gobierno del FMLN. También en este contexto, es importante resaltar que es poco lo que se conoce de la verdadera historia de los pueblos indígenas y por esto, es esencial desarrollar un proceso de esclarecimiento de ésta.

II. La realidad de los pueblos indígenas, especialmente el hecho de que sus expresiones culturales están cerca de desaparecer, nos reta y urge a trabajar sistemáticamente en conjunto con y por estos pueblos y con el resto de la población para promover un enfoque de interculturalidad. El Salvador debe velar porque esta historia no finalice con la desintegración de los pueblos originarios, lo cual podría constituirse en la culminación del genocidio de 1932.

III. Los Gobiernos del FMLN han iniciado un camino para promover los derechos de los pueblos indígenas mediante el reconocimiento de que somos un país

54. Virginia Tilley en su libro Seeing Indians: A study of Race, Nation, and Power in El Salvador, E.U., (Univesrity of New Mexico Press, 2005) registra más de 40 levantamientos de indígenas salvadoreños durante y después de la colonia. Casi siempre, estos levantamientos tuvieron como respuesta, grandes masacres de indígenas. 
multicultural y pluriétnico, la apertura de espacios estatales de participación de estos pueblos y sus representantes, la promoción de la reforma constitucional donde han sido reconocidos y el trabajo de políticas públicas y planes próximos a oficializarse. El lanzamiento de planes y políticas públicas para los pueblos indígenas, la ratificación del Convenio 169 de la OIT así como la culminación de la política y la ley de cultura, nos darán un marco que pueda sustentar cualquier avance sostenido en los derechos de los pueblos indígenas a futuro.

IV El reconocimiento legal a los pueblos indígenas implica aterrizar en procesos que puedan cambiar la realidad de estos pueblos para alcanzar niveles dignos de cumplimiento de sus derechos, convirtiéndolos así en autores de su propio destino. Se trata de trascender el "ser negado" al "ser" en toda su plenitud y esto nos involucra a todos los salvadoreños; implica también, que nos reconozcamos como nación que posee esta herencia mesoamericana. Por su parte, varios países de Sudamérica, ante la difícil realidad que urge respuestas, han retomado la sabiduría ancestral, que se basa en los principios armónicos, en el reconocimiento mutuo de los diferentes grupos humanos, en reconocer a la Madre Tierra como un ser vivo, todo esto para replantear el estado y dentro de éste, a la sociedad. En aquellas latitudes estos principios se agrupan bajo el Sumak Kawsay, ${ }^{55}$ es decir, el Buen Vivir; pero los pueblos indígenas de Centroamérica, también retoman estos principios que igual se encuentran en la cultura ancestral mesoamericana. De esta cuenta, los pueblos indígenas de Guatemala le llaman el Utzil ${ }^{56}$ (el estado de paz y bien) y los pueblos de El Salvador le han llamado el Yec Ineme ${ }^{57}$ (bienestar armónico). En estos momentos difíciles para el país, donde la violencia, los problemas económicos y el problema medioambiental presentan niveles de suma preocupación, es el tiempo de volver la vista hacia nuestros orígenes, hacia esa sabiduría que seguramente nos proveerá de elementos para buscar y encontrar soluciones a los problemas actuales aludidos. 


\section{Bibliografía}

Alcaldía Municipal de Nahuizalco. Ordenanza Municipal sobre Derechos de las Comunidades Indígenas asentadas en el municipio de Nahuizalco. El Salvador, 2010.

Asamblea Constituyente. Constitución de la República de El Salvador. Decreto No. 38. 1983. El Salvador, 1983.

Asamblea Legislativa de la República de El Salvador. Decreto Legislativo 121 del 11 de julio de 1932. El Salvador, 1932.

Consejo Nacional para la Cultura y el Arte, CONCULTURA. Perfil de los Pueblos Indígenas en El Salvador. El Salvador, 2003.

Escalante Arce, Pedro Antonio. Códice Sonsonate, (El Salvador: Dirección de Publicaciones e Impresos, Consejo Nacional para la Cultura y el Arte, Ministerio de Educación). El Salvador, 1992.

Federación Luterana Mundial. Informe Sombra de los $9^{\circ}, 10^{\circ}, 11^{\circ}, 12^{\circ}$, y $13^{\circ}$ informes periódicos de la República de El Salvador presentado Ante el Comité para la Eliminación de la Discriminación Racial de la Organización de las Naciones Unidas. El Salvador, 2006.

Marroquín, Alejandro Dagoberto. “El Problema Indígena en El Salvador”. América Indígena, año XXXV núm. 4. México, Octubre-diciembre de 1975. México, 1975.

Marielba Herrera y Herbert Erquicia. Aproximación Etnográfica al Culto Popular del Hermano Macario en Izalco, Sonsonate. El Salvador. Universidad Tecnológica. El Salvador, 2010.

Ministerio de Salud. Propuesta de Política Nacional de Salud Intercultural. Ministerio de Salud. (Documento para Consulta Pública). El Salvador 2015.

Organización de las Naciones Unidas, ONU. Comité para la Eliminación de la Discriminación Racial. Examen de los Informes Presentados por los Estados Partes de conformidad con el artículo 9 de la Convención. Observaciones finales del Comité para la Eliminación de la Discriminación Racial, El Salvador. (CERD/C/SLV/14-15). ONU, 2010.

Organización de las Naciones Unidas, ONU. Convención de los Derechos del Niño (ratificada el 27 de abril de 1990). El Salvador, 1990.

Organización de las Naciones Unidas, ONU. Convención para la Prevención y Sanción del Delito de Genocidio. ONU, 1948.

Organización de las Naciones Unidas, ONU. Convenio 169 de la OIT Sobre Pueblos Indígenas y Tribales en Países Independientes. ONU, 1989.

Organización de las Naciones Unidas ONU. Convenio sobre Diversidad Biológica (ratificado el 23 de marzo de 1994). El Salvador, 1994.

Organización de las Naciones Unidas, ONU. Declaración de las Naciones Unidas sobre los Derechos de los Pueblos Indígenas. ONU, 2007.

Organización de las Naciones Unidas. Informe del Relator Especial sobre los Derechos de los Pueblos Indígenas, James Anaya, sobre la situación de los pueblos indígenas en El Salvador. ONU, 2013.

Secretaría de Cultura de la Presidencia. Propuesta de Política Pública para los Pueblos Indígenas de El Salvador. El Salvador, 2015. 
Tilley,Virginia. Seeing Indians: A study of Race, Nation, and Power in El Salvador. Univesrity of New Mexico Press. Estados Unidos de Norteamérica, 2005.

\section{Sitios web consultados}

Arias Gómez, Jorge. Anastasio Aquino, Recuerdo, Valoración y Presencia (Cuadernos de El Socialista Centroamericano Número 19) http://www.elsoca.org/pdf/esca/ Cuaderno\%20Anastasio\%20Aquino.pdf (consultada el 22 de octubre de 2015).

Congreso de la República del Perú. Archivo Digital de la Legislación del Perú. Leyes de Indias. http://www.leyes.congreso.gob.pe/Documentos/Leylndia/0206001.pdf (consultada el 17 de septiembre de 2015).

Convención Internacional Relativa a los Congresos Indigenistas Interamericanos y al Instituto Indigenista Interamericano http://proteo2.sre.gob.mx/tratados/ ARCHIVOS/I.I.I.pdf (consultada el 13 de octubre de 2015).

El Instituto Indigenista Interamericano: Sus actividades en el período 1943-1945 http: / / www.jstor.org/stable/40977597?seq=1\#page_scan_tab_contents (consultada el 13 de octubre de 2015).

López Bernal, Carlos Gregorio. Hacer Historia en El Salvador. Núm. 01 año 01. Revista electrónica de estudios históricos.. El Levantamiento de los Indios Nonualcos en 1832. Hacia una nueva interpretación. 26 https://www.academia. edu/7112047/El_levantamiento_de_los_indios_nonualcos_en_1832._Hacia_ una_nueva_interpretaci\%C3\%B3n._Hacer_historia_en_El_Salvador._Revista_ electr\%C3\%B3nica_de_estudios_hist\%C3\%B3ricos_no._1_2008_(Consultada el 17 de septiembre de 2015).

NationalGeographic. Las Leyes Nuevas, un alegato a favor de los indios. http://www. nationalgeographic.com.es/articulo/historia/actualidad/7799/las_leyes_ nuevas_alegato_favor_los_indios.html (consultada el 3 de noviembre de 2015)

Olmedo Lope, Horacio José.Breves Consideraciones al Régimen de Titulación de Inmuebles en la Legislación Salvadoreña. Tesis Doctoral presentada en 1969.Universidad de El Salvador, Facultad de Jurisprudencia y Ciencias Sociales. Corte Suprema de Justicia, Biblioteca Judicial Dr. Ricardo Gallardo.

http: //www.csj.gob.sv/BVirtual.nsf/3db6532d39e032fd06256b3e006d8a73/d156829216 41b25306256b3e00747a4d?OpenDocumentLey de Extinción de Comunidades del 23 de febrero de 1881 (consultada el 17 de septiembre de 2015). 